\title{
A STUDY ON THE GAS-LIQUID MIXTURE FLOW CHARACTERISTICS INSIDE IN-LINE TYPE SUBSEA SEPARATOR
}

\author{
Y.J. KIM, N.S. WOO \& S.M. HAN \\ Korea Institute of Geoscience and Mineral Resources, Daejeon 305-350, Republic of South Korea.
}

\begin{abstract}
The implementation of subsea separation and liquid boosting is becoming a common development scheme for the exploration of deep water fields. Subsea separation is an attractive and economic solution to develop deep offshore fields producing fluid without hydrate or wax. Recently the subsea separation system is designed for a water depth of $3,000 \mathrm{~m}$ and internal design pressure up to $690 \mathrm{bar}$. Development and application of subsea separation system are relatively common in the developed countries and many studies have been conducted previously, but it is still a new field in Korea and this is the significance of this study. In this study, gas-liquid mixture flow characteristics inside in-line type subsea separation system are investigated by numerical and experimental studies for the development of subsea separator. For the subsea separator designed in this study, it is predicted to have a separating efficiency of $70 \%$.

Keywords: offshore installation, subsea processing system, subsea separation system.
\end{abstract}

\section{INTRODUCTION}

In recent years, subsea processing, and more specially subsea separation, has been recognized as one of the most promising technology developments in the offshore industry.

Performing a part of the required separation process at the seabed, can enable a more effective production and reduce the need for topside processing capacity. Subsea separation has already been applied for both a greenfield development as well as a retrofit solution for a field in production. The solution can contribute to a better environment and higher revenue. For maturing fields, the production and recovery can increase cost-efficiently by improving and prolonging the use of existing infrastructure. Separation and re-injection of bulk water will free up space in flowlines and risers and eliminate the need for topside equipment upgrades.

Currently, subsea processing projects can be found in nearly every major offshore oil and gas region in the world, with the North Sea and offshore Brazil (Campos and Espirito Santo basins) experiencing the most activity to date. While still an emerging market, with the number of installed systems relatively small, recognition of the potential returns, and hence the level of acceptance of subsea processing technologies, continues to increase. Subsea processing is now appearing in development options for many industry projects [1].

Subsea separation and processing systems development and field application projects are relatively common in a few developed countries and many studies have been conducted previously [2-5], but it is still a new field in Korea and this is the motivation of this study.

In this study, vertical type subsea separation system simulation study is carried out as a process of subsea separation system development especially, focused on the investigation of gas/liquid mixture flow characteristics inside separators. 


\section{SUBSEA SEPARATING SYSTEM}

\subsection{Subsea processing technology}

Raw petroleum products consist of a variable mixture of oil, condensate (light oils), natural gas, formation water, and formation solids (sands). Many of the technological challenges associated with petroleum production in the deep sea are a result of the mixture of these components.

In particular, the presence of water along with gas in the product stream increases the potential for hydrate formation and subsequent clogging of the pipelines. Figure 1 shows the general subsea processing solution together with multiphase pumping and subsea separating.

There are a number of reasons why operators may choose to install subsea processing equipment. First of all, most subsea processing will increase the recovery from the field, thus increasing profits. Additionally, by enhancing the efficiency of flowlines and risers, subsea processing contributes to flow management and assurance. Also, subsea processing enables development of challenging subsea fields, while reducing topside expenditures for equipment. Furthermore, subsea processing converts marginal fields into economically viable developments [6].

Subsea processing can encompass a number of different processes to help reduce the cost and complexity of developing an offshore field. The main types of subsea processing include subsea water removal and re-injection or disposal, single-phase and multi-phase boosting of well fluids, sand and solid separation, gas/liquid separation and boosting, and gas treatment and compression.

Saving space on offshore production facilities, separation of water, sand and gas can now be performed subsea. Subsea separation reduces the amount of production transferred from the seafloor to the water's surface, debottlenecking the processing capacity of the development.

In the configuration of subsea processing system, four types of subsea processing technology can be classified. Technologies that are currently being implemented in deep water include multiphase pumps (Type 1) and partial separation with pumping (Type 2). Multiphase pumping systems are proven technologies, whereas Type 2 systems have seen limited use.

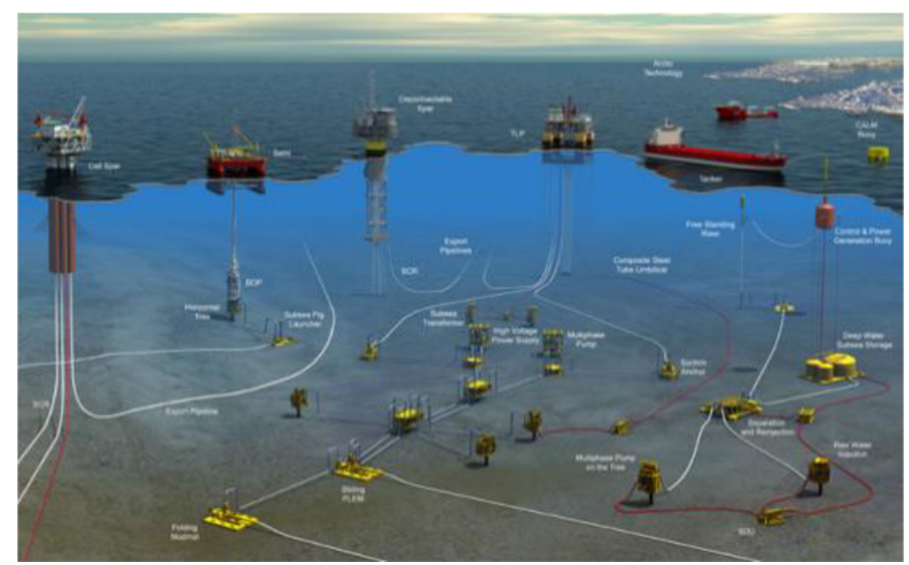

Figure 1: Subsea processing system (Seadiscovery.com). 
Technologies currently being developed for future applications of separators, scrubbers, and pumps that allow complete separation of the production stream at the seabed (Type 3 ). The most advanced systems (Type 4) are likely to include multistage separation and fluid treatment with the production of export quality oil and gas. The key environmental issue involved in the implementation of these technologies is the handling and disposal of the produced waters and sands [7].

\subsection{Subsea separation system}

The initially subsea production involved fluid flow through wellhead, valves and pipework. Subsea production is a significant mind set change in exploiting reserves close to existing infrastructure economically. In increasingly deeper water depths, with no nearby infrastructure, more processing is required locally.

Separating oil from one or all of the co-produced products including water, solids, and gas is the basis for future subsea separation. Water separation has attracted the highest priority due to the largest benefits to be gained in the short term. Solids separation is increasingly important especially in locations where solids production probability is high. Gas separation allows for a totally integrated separation system, bringing topsides to the sea floor.

Figure 2 shows that the subsea separation system is based on either a two-phase (gas/liquid) or three-phase (oil/gas/water) separation process. These systems have the potential to significantly reduce costs on offshore platforms by placing the equipment necessary to separate reservoir products on the seafloor. By placing the equipment on the seafloor, the capacity to process oil on the platform should increase and the need to separate potentially large volumes of produced water on the platform is eliminated.

Conventional phase separation technologies usually employ gravity separation in a large tank. As oil and gas production regions expand from shallow water to deep water, a separator designed for the deep water has confronted a challenge. Conventional gravity separators are not suitable for deep water uses, because of the thick outer wall of the tank enough to endure extreme deep water conditions, which may lead to unrealistic sizes and weights of the separator.

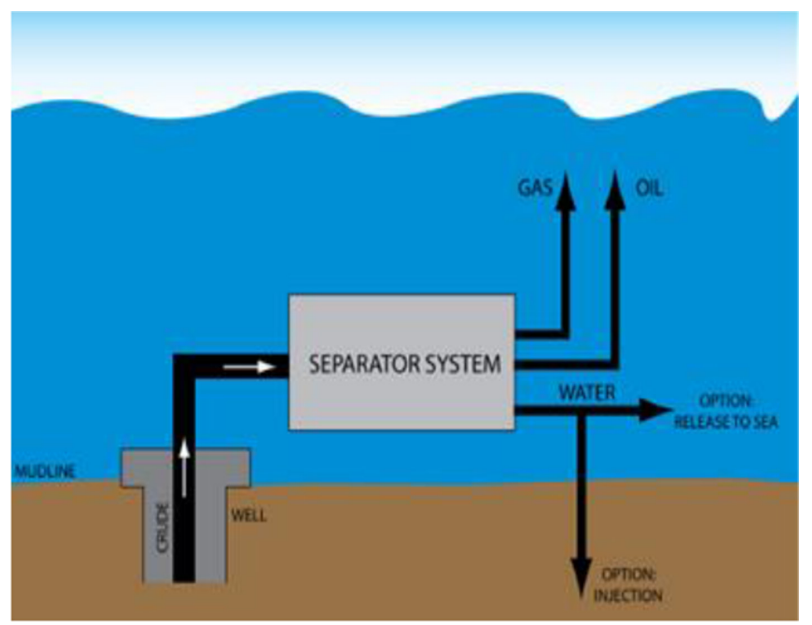

Figure 2: Subsea separation system [7]. 
In order to resolve this matter, in-line types of the separator have been extensively studied. Liquid containing gas produced in an oil well passes through an in-line separator, and experiences a swirling flow by a flow-turning device in a pipe. The resultant momentum enables to separate gas phases with lower density based on the center of the pipe [8].

In-line subsea separators can be categorized into several types according to their phase separation purposes. Devices for gas-liquid separation include Degasser, Demister, Deliquidiser, and Phasesplitter. Devices for liquid-liquid separation include Dewaterer, ElectroCoalescer and Hydrocyclone. A device for removing sand contains Desander [9].

An in-line type of the Degasser system is displayed in Fig. 3. Degasser is a device that separate gas phases from a liquid stream. The liquid containing gas phases is separated into liquid and gas phases, by being swirled in the center of the pipe and passing through a pipe with a small diameter. Other systems are designed with similar structures.

Comparing with a gravity separator, the major advantages of the in-line type separators are highly efficient phase separation, straightforward possible miniaturization, compatibility with existing equipment.

\section{NUMERICAL CALCULATION}

A pipe used in the numerical analysis has a diameter of $100 \mathrm{~mm}$ and a total length of 2,000 mm. As shown in Fig. 4, we fabricated an internal swirl element (ISE), a swirl flow generator in the pipe, benchmarking a product from ASCOM. Mixtures introduced at the inlet are accelerated while passing by a vane area. Total 9 blades contribute the separator to generate swirling flow. The part of ISE near to the inlet is called "nose", and near to the outlet is called "tail".

The governing equations used in this paper are as follows.

Continuity Equation:

$$
\frac{\partial}{\partial t}\left(\alpha_{q} \rho_{q}\right)+\nabla \cdot\left(a_{q} \rho_{q} \vec{v}_{q}\right)=\sum_{p=1}^{n}\left(\dot{m}_{p q}-\dot{m}_{q p}\right)
$$

$\alpha_{q}$ and $\vec{v}_{q}$ is the volume fraction and the velocity of the phase $q, \dot{m}_{p q}$ represents the mass transfer from the phase $p^{\text {th }}$ to the phase $q^{\text {th }}$.

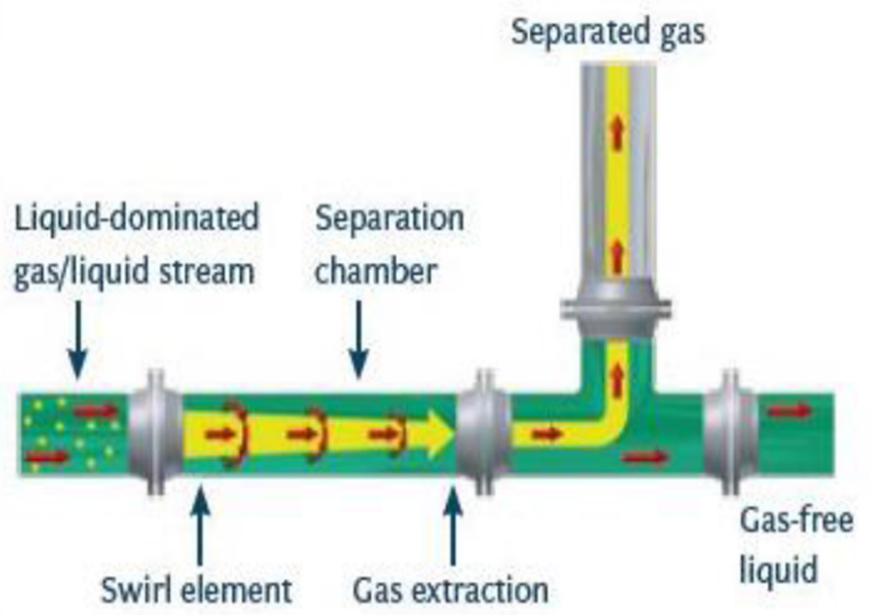

Figure 3: In-line type degasser system (FMC technology). 


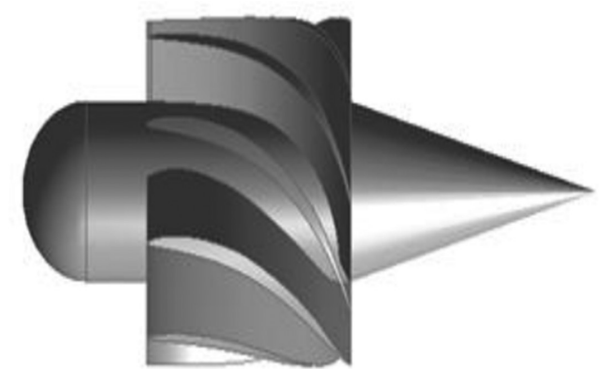

Figure 4: ISE 3D geometry.

Momentum Equation:

$$
\begin{gathered}
\frac{\partial}{\partial t}\left(\alpha_{q} \rho_{q} \vec{v}_{q}\right)+\nabla \cdot\left(\alpha_{q} \rho_{q} \vec{v}_{q} \vec{v}_{q}\right)=-\alpha_{q} \nabla p+\nabla \cdot \bar{\tau}_{q}+\alpha_{q}+\alpha_{q} \rho_{q} \vec{g}, \\
+\sum_{p=1}^{n}\left(\vec{R}_{p q}+\dot{m}_{p q} \vec{v}_{p q}-\dot{m}_{q p} \vec{v}_{q p}\right)+\left(\vec{F}_{q}+\vec{F}_{l i f t, q}+\vec{F}_{w l, q}+\vec{F}_{v m, q}+\vec{F}_{t d, q}\right)
\end{gathered}
$$

$\bar{\tau}_{q}$ is a stress-strain tensor of the phase $q^{\text {th }}$, it is defined as follows.

$$
\bar{\tau}_{q}=\alpha_{q} \mu_{q}\left(\nabla \vec{v}_{q}+\nabla \vec{v} T_{q}\right)+\alpha_{q}\left(\lambda_{q}-\frac{2}{3} \mu_{q}\right) \nabla \cdot \vec{v}_{q} \bar{I}
$$

$\mu_{q}$ and $\lambda_{q}$ indicate the viscosity and the shearing force of the phase $q, \bar{I}$ is the unit tensor.

Energy Equation:

$$
\begin{aligned}
\frac{\partial}{\partial t}\left(\alpha_{q} \rho_{q} h_{q}\right)+ & \nabla \cdot\left(\alpha_{q} \rho_{q} \vec{u}_{q} h_{q}\right)=\alpha_{q} \frac{\partial \rho_{q}}{\partial t}+\bar{\tau}_{q}: \nabla \vec{u}_{q}-\nabla \cdot \vec{q}_{q}+S_{q} \\
& +\sum_{p=1}^{n}\left(Q_{p q}+\dot{m}_{p q} h_{p q}-\dot{m}_{q p} h_{q p}\right)
\end{aligned}
$$

$h_{q}$ is the specific enthalpy of the phase $q^{t h}, \vec{q}_{q}$ is the heat flux.

Turbulence models can be divided into multiple categories depending on how they treat viscosity, but the most common model is the $\kappa-\varepsilon$ model. The $\kappa-\varepsilon$ model is based on the eddy-viscosity concept similar to the molecular motions of Newtonian fluid, and performs its analysis under the "isotropy" assumption.

However, because turbulent flows in the separator with high Reynolds numbers are expected, and have strong streamline curvatures and anisotropy, the $\kappa-\varepsilon$ model is not appropriate for analysis. Instead, we employed the Reynolds stress model (RMS), more suitable to imitate internal numerical values of the separator, which generate a strong swirling flow [10].

In order to analyze computational fluid dynamics (CFD), we applied the Eulerian model, suitable for multiphase analysis, in which we set crude oil as a continuous phase, and natural gas as a dispersed phase. A commercially available code, ANSYS CFX Ver. 14.5 was used.

Since the momentum equation of the multiphase flow model includes the interaction force, we employed the Schiller and Naumann equation as a drag force equation. The ISE was fixed 
Table 1: Material properties of working fluid.

\begin{tabular}{lll}
\hline Density $(\mathrm{kg} / \mathrm{m} 3)$ & Crude oil & 790 \\
& Natural gas & 0.7 \\
Dynamic viscosity $(\mathrm{kg} / \mathrm{m} \mathrm{s})$ & Crude oil & 0.004277 \\
& Natural gas & 0.00003 \\
Surface Tension $(\mathrm{n} / \mathrm{m})$ & 0.035 &
\end{tabular}

and the volumetric ratio of the mixtures introduced at the inlet are $45.5 \%$ crude oil, $54.5 \%$ natural gas. This ratio is according to the assumption by the experimental article of ASCOM, which describes water be filtered in the first separator [11].

We set the pressure at the inlet, 15 bar and at the outlet 13 bar. The properties of the working fluid for the numerical analysis are listed in Table 1.

\section{RESULTS AND DISCUSSION}

In this study, we aim to fabricate a swirling flow generator for the optimized gas-liquid flow. As a result, Figs 5 and 6 demonstrate that natural gas with a relatively lower density concentrates to the middle of the pipe, while crude oil with relatively higher density disperses toward the pipe.

In order to verify our analysis, we compared our results with results from Slot for the water-air analysis [12]. Figure 7 shows the comparison results of radial direction velocities on a point that is $440 \mathrm{~mm}$ away from the inlet. The left shows the results of slot, while the right displays the numeral calculation.

In order to obtain the optimized form of ISE to separate natural gas - crude oil phases, we performed additional numerical analysis on Case 1: Basic configuration ( 9 blades, outlet angle: $\left.32.4^{\circ}\right)$, Case 2 ( 8 Blades), Case 3 (10 blades), Case 4 (outlet angle $+1^{\circ}$ ), and Case 5 (outlet angle $+2^{\circ}$ ) by setting blades and outlet angles as variables. The results as the natural gas volume fraction are demonstrated in Fig. 8.

For intuitive comparison, the volume fraction values of dominant flows on the location A (center of the pipe), and B (near to the wall of the pipe) as depicted in Fig. 9, are plotted in Figs 10 and 11.

As a result, Case 1 shows the highest efficiency of ISE for phase separation in the center of the pipe, while Case 5 shows higher efficiency of ISE near the wall of the pipe. The large

Gas.Volume Fraction

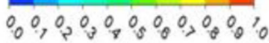

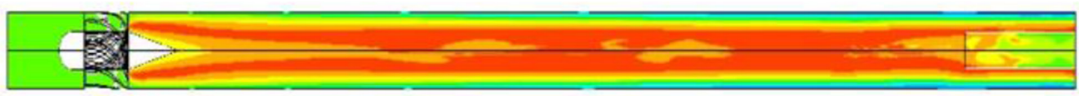

Figure 5: Volume fraction distribution of natural gas.

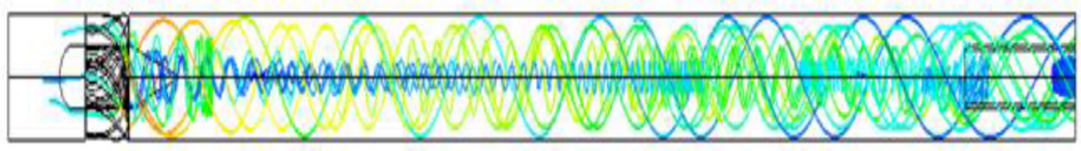

Figure 6: Streamline of natural gas superficial velocity. 


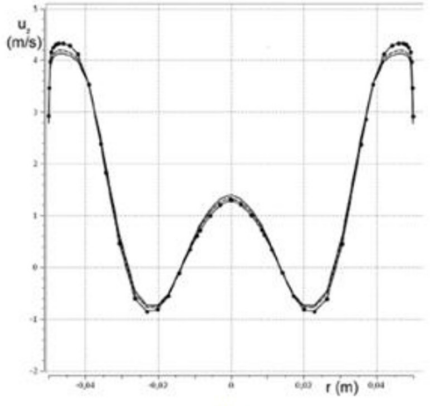

(a) Slot

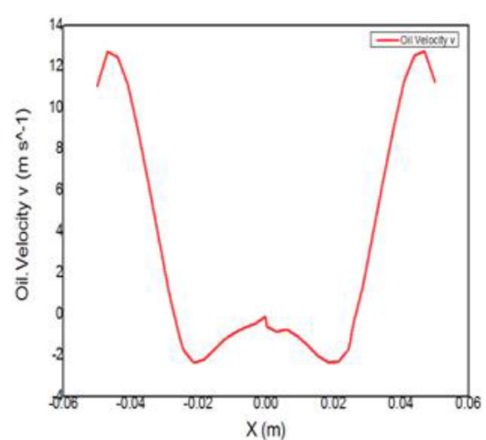

(b) calculated

Figure 7: Comparison of radial distribution of continuous phase velocity at $\mathrm{x}=0.44 \mathrm{~m}$.

Gas. Volume Fraction

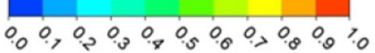

\section{俩}

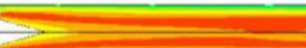

(a) case 1

(b) case 2

(c) case 3

(d) case 4

(e) case 5

Figure 8: Natural gas volume fraction of each case.

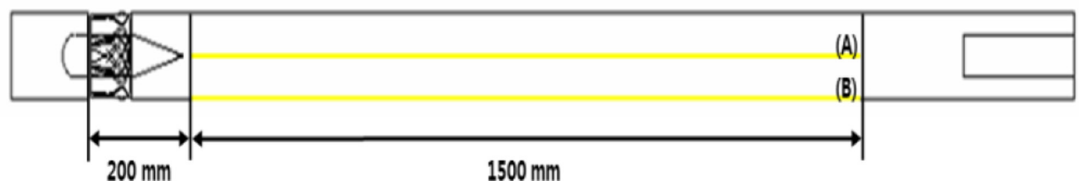

Figure 9: Position of A, B. 


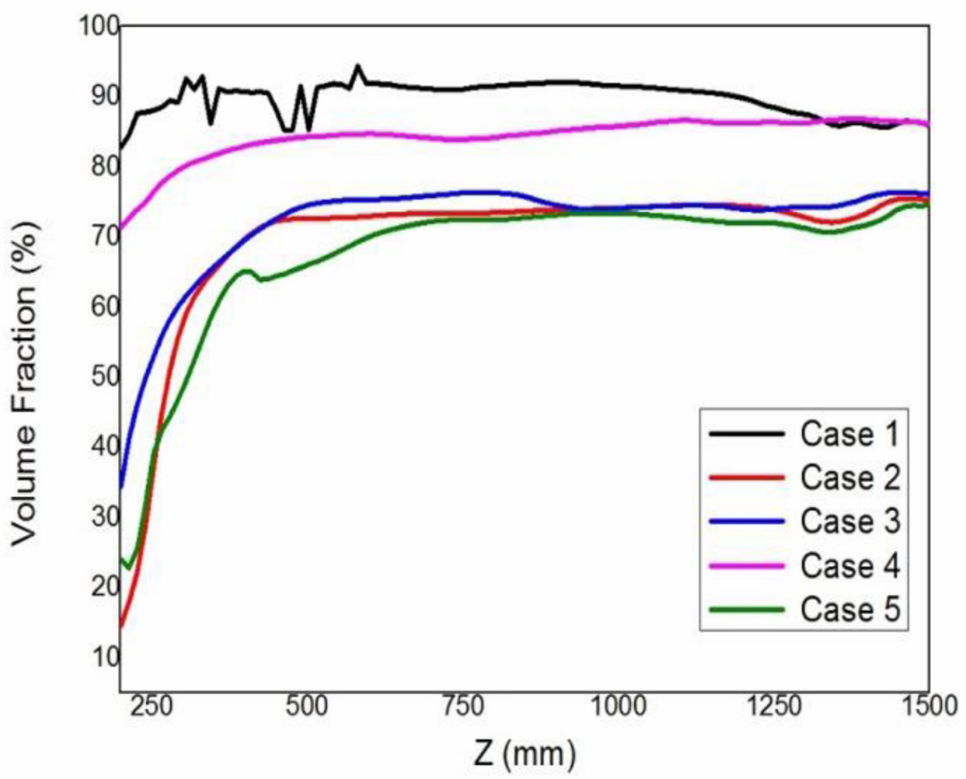

Figure 10: Natural gas volume fraction of position A.

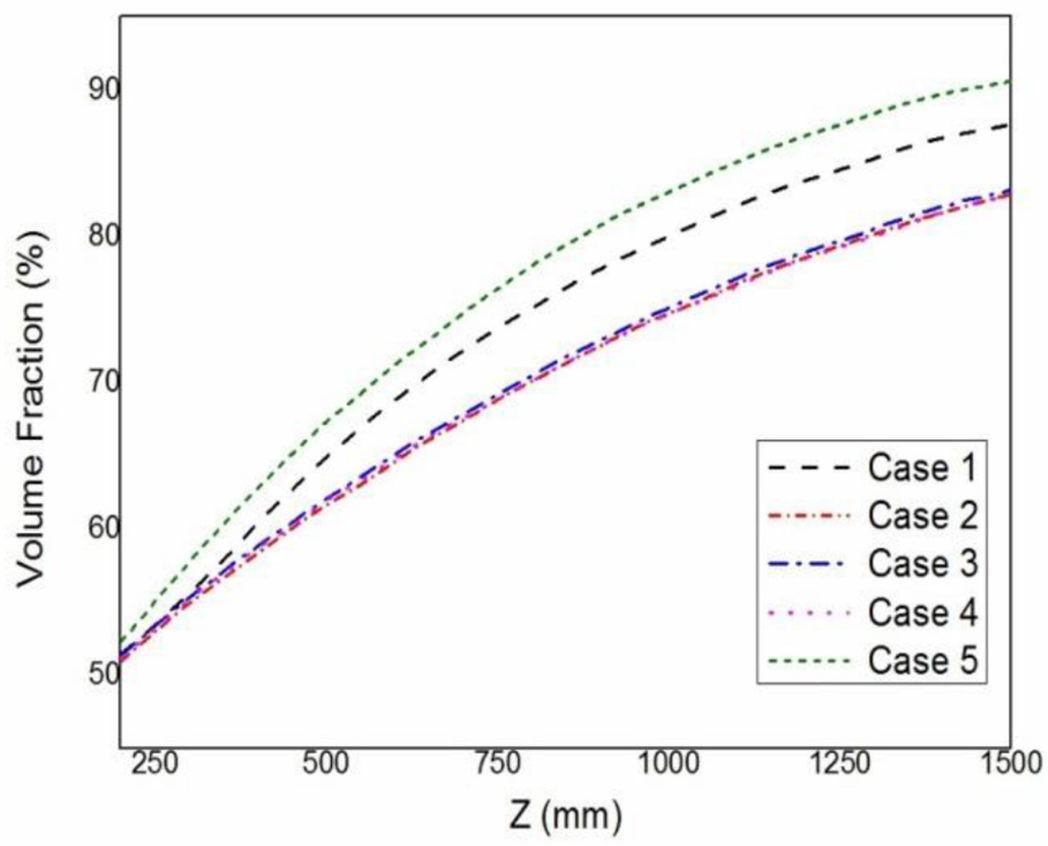

Figure 11: Crude oil volume fraction of position B. 
momentum of the flow to the outlet angle change is believed to prevent the flow from concentrating toward the center.

\section{CONCLUSIONS}

We conclude, based on the numerical analysis of the multiphase flow in the in-line separator, as follows:

1. We verified that the lower density natural gas concentrates toward the center of the pipe, while the higher density crude oil tends to disperse toward the periphery of the inner pipe-wall.

2. In order to verify our analysis, we obtained radial flow fields similar to the result from Slot for the water-air analysis.

3. In order to obtain the optimized ISE for gas-liquid phase separation, additional analysis was performed. As a result, the Case 1 configuration is shown to be most suitable for phase separation, and its phase separation efficiency is approximately $70 \%$.

4. Additional analyses are required to obtain the best optimized ISE configuration for phase separation.

\section{ACKNOWLEDGMENTS}

This research was supported by the Development of 500 Mpa URF \& SIL 3 Manifold and Subsea System Engineering for Deepsea Field Project (13-9806) of the KIGAM funded by the Ministry of Trade, Industry and Energy of Korea.

\section{REFERENCES}

[1] Michaelsen, J., Innovative technology for ultra deepwater gravity-based separators. Offshore Technology Conference 15175, 2003. http://dx.doi.org/10.4043/25698-MS

[2] Di, S.R., Abrand, S., Shaiek, S., Butin, N., Riou, X. \& Decrin, M.K., A novel gas/liquid separator to enhance production of deep water marginal fields. Offshore Technology Conference 21394, 2011.

[3] Bymaster, A.S., Olson, M.D., Grave, E.J., Svedeman, S.J., Viana, F., Mikkelsen, R. \& Akdim, R., High-pressure gas-liquid separation: an experimental study on separator performance of natural gas streams at elevated pressures. Offshore Technology Conference 21781, 2011.

[4] Hannisdal, A., Westra, R., Dkdim, R., Bymaster, A., Grave, E. \& Teng, D., Compact separation technologies and their applicability for subsea field development in deep water. Offshore Technology Conference 23223, 2012.

[5] Rune, F., Toine, H. \& Robert, C., Compact subsea separation system with integrated snad handling. Offshore Technology Conference 16412, 2004.

[6] Simon, D., Statoil's experience with and plans for subsea processing. Deep Offshore Technology International, 2010.

[7] Thomas, M.G., Theodore, E.D., Jim, C., John, R., Colleena, P., Jeffrey, B. S., Gilbert, R., Stuart, S. \& Todd Ririe, G., Effects of Subsea Processing on Deepwater Environments in the Gulf of Mexico, OCS Study, MMS 2008-022, 2008.

[8] Bell, J.M., Chin, Y.D. \& Hanrahan, S., State of the art of ultra deepwater production technologies. Offshore Technology Conference 17615, 2005. 
[9] Woo, N.S., Park, J.M., Kwon, J.K., Kim, Y.J., Kim, S.S. \& Jung, S.Y., A study on the subsea separation system development. Transactions of the KSAE (The Korean Society of Automotive Engineers), pp. 2396-2400, 2013.

[10] Yang, H.C. \& Ryou, H.S., The effect of turbulence model on the flow field and the spray characteristics. Transactions of the KSAE (The Korean Society of Automotive Engineers), 5, pp. 87-101, 1997.

[11] Schook, R. \& Thierens, D., De-bottlenecking of mature field production through the use of very compact and efficient separation equipment, topside or subsea. Offshore Technology Conference 21617, 2011.

[12] Slot, J.J., Campen, L.J.A.M., Hoeijmakers, H.W.M. \& Mudde, R.F., In-line oil-water separation in swirling flow. 8th International Conference on CFD in Oil \& Gas, Metallurgical and Process Industries SINTEF/NTNU at Trondheim, CFD11-121, 2011. 